\title{
Heroe, Egregio, para contrabaixo e cravo: aspectos didáticos e interpretativos em uma transcrição de uma cantata do repertório colonial brasileiro
}

\author{
Fausto Borém (UFMG) \\ fborem@ufmg.br \\ Cecília Nazaré de Lima (UFMG) \\ cecilianl@ufmg.br
}

Resumo: 0 ainda restrito acesso a partituras e concertos do vasto repertório musical brasileiro dos séculos XVIII e XIX e sua instrumentação estereotipada (quase sempre obras vocais religiosas com acompanhamento orquestral) são obstáculos para sua inclusão nos currículos dos cursos de música no país e sua apreciação por um público mais amplo. Uma alternativa para mudar este quadro é a transcrição de obras desse repertório e adaptação de sua instrumentação para grupos de câmara menores, com exclusão até mesmo da voz na sua instrumentação. Essas transcrições podem proporcionar, de maneira mais eficaz, o contato e a experimentação com as assim-chamadas práticas de performance historicamente informadas (Historically Informed Performance ou HIP), seja a partir da adaptação de referências (auditivas e textuais) já consolidadas na interpretação do repertório europeu, seja a partir da análise de elementos históricos, formais e possíveis figuras de retórica. No presente trabalho, estas questões são abordadas no Recitativo e Aria da cantata acadêmica Heroe, egregio, douto, peregrino (anônimo, Salvador, 1759) para soprano, dois violinos e baixo contínuo, transcrita para um instrumento de cordas orquestral solista (violino, viola, violoncelo ou contrabaixo) e cravo.

Palavras-chave: práticas de performance historicamente informadas; música colonial brasileira; Cantata Heroe, egregio; transcrição musical; cordas orquestrais, cravo.

\section{Heroe, Egregio for double and harpsichord: interpretive and pedagogical aspects in a transcription of a cantata from the Brazilian colonial repertory}

\begin{abstract}
The still limited access to scores and concerts of the vast Brazilian music repertoire from the eighteenth and nineteenth centuries and its stereotyped instrumentation (almost always sacred vocal music with orchestral accompaniment) are obstacles for the inclusion of this repertory in the country's instrumental music curricula and its appreciation by a wider audience. An alternative for this situation is the transcription of works and change of their instrumentation to fit smaller chamber formations, including those without singing. Moreover, these transcriptions could also allow the contact and experimentation with the so-called Historically Informed Performance (HIP), departing either from the adaptation of (aural and textual) references already consolidated in the interpretation of the European repertoire or from the analysis of historical and formal elements and rhetorical figures. This article addresses these questions in Recitativo e Aria from the academic cantata Heroe, egregio, douto, peregrino (anonymous, Salvador, 1759) for soprano, two violins and basso continuo, transcribed for a solo orchestral string instrument (violin, viola, violoncello or double bass) and harpsichord.

Keywords: Historically Informed performance; Brazilian colonial music; Cantata Heroe, egregio; music transcription; orchestral strings, harpsichord.
\end{abstract}




\section{1- Introdução:}

As crescentes e significativas contribuições da musicologia histórica brasileira que, grosso modo, já abrangem resultados de pesquisadores de três gerações, têm chegado aos músicos e público por meio da redescoberta e publicação de manuscritos e realização de concertos do repertório colonial e imperial brasileiro. Entretanto, além do acesso limitado às partituras e do pequeno número de concertos, há um outro obstáculo para que a música brasileira deste período faça parte do dia-a-dia das graduações, pós-graduações ou cursos livres de música, especialmente no caso dos instrumentistas, que perfazem o maior número de alunos. Por ter sido patrocinada quase que exclusivamente pela igreja, a grande maioria das obras deste repertório é constituída de música religiosa vocal (coro; às vezes com solistas) com acompanhamento de orquestra (em que predominam cordas, flautas e trompas). Geralmente, as cordas orquestrais são tratadas homofonicamente, com destaques ocasionais que, via de regra, privilegiam os primeiros violinos. Mesmo mais tarde, ao longo do século XIX, com a crescente ênfase nas canções e na ópera, a escrita instrumental de câmara brasileira (especialmente a que não inclui o teclado) continuou em segundo plano. Como resultado desse quadro, do ponto de vista didático e do desenvolvimento dos currículos das escolas voltadas para a formação de instrumentistas, verifica-se um afastamento e desconhecimento desse vasto acervo musical, apenas mitigado por esporádicos concertos em que as partes individuais dos instrumentos não parecem muito atraentes aos que as tocam.

0 desconhecimento sobre esses compositores e seus estilos por parte da maioria dos alunos e professores de música no Brasil (entre os quais se incluem os presentes autores) motivou a abertura de uma nova vertente no Projeto Pérolas e Pepinos da Performance Musical (para mais detalhes, veja Diretório dos Grupos de Pesquisa no site do $(\mathrm{NPq})$. 0 procedimento da transcrição musical foi escolhido como meio para colocar um número maior de músicos e público em contato com o repertório que se estende desde o descobrimento do Brasil até pelo menos o início do século XX. As transcrições musicais são entendidas aqui como um procedimento de re-leitura de partituras envolvendo uma mudança idiomática de instrumentação (no presente estudo, o grupo original se reduz a contrabaixo e cravo) e, muitas vezes, mudança de tonalidade (no presente estudo, de Fá Maior para Ré Maior) e pequenos ajustes composicionais ao nível das articulações, dinâmicas e ornamentações. Em que pese a visão purista urtext de se considerar apropriada apenas a escrita dos manuscritos originais, o procedimento da transcrição foi amplamente utilizado pelos principais compositores europeus dos períodos barroco, clássico e romântico e, mesmo, do século XX (BORÉM, 1998). Dentro deste projeto, buscou-se, num primeiro momento, exemplificar o desenrolar histórico de nossa música erudita, selecionando-se compositores ou obras relevantes como as primeiras partituras encontradas no Brasil - a exemplo da cantata acadêmica ${ }^{1}$ Heroe, egregio e a Sonata
Sabará, ${ }^{2}$ ambas de compositores anônimos - e de autores como João de Deus de Castro Lobo, Sigismund Neukomm, Gabriel Fernandes da Trindade, João Rodrigues Cordeiro e Carlos Gomes, dentre outros.

Além destes obstáculos, outra questão que emerge na aprendizagem e interpretação deste repertório é o pouco contato dos instrumentistas de cordas brasileiros com as chamadas práticas de performance historicamente informadas (ou HIP, historically informed performance). Esse tipo de prática instrumental, historicamente fundamentada e já bastante difundida na Europa, inclui tanto a utilização de instrumentos e acessórios característicos de cada período musical (e.g., arcos barrocos, de transição e clássicos, cordas de tripa com afinações mais baixas, instrumentos com braços mais próximos do tampo etc.), como também procedimentos estilísticos específicos na realização musical de cada período (e.g., articulações e dinâmicas não explicitadas pela notação musical, ênfases derivadas da retórica musical, realização de ritmos e de ornamentação, elaborações de caráter improvisatório etc.). Em função do caráter didático desta proposta, propõe-se aqui uma livre experimentação com as HIP, especialmente para os intérpretes que não dispõem de instrumentos adaptados e acessórios próprios dos períodos barroco e clássico, o que é a realidade para a grande maioria dos instrumentistas no Brasil. Nesse sentido, consideramos pontos de partida a adaptação, ao repertório brasileiro, de referências (auditivas e textuais) já consolidadas na interpretação do repertório europeu, a análise de elementos históricos e formais, a relação texto-música e a identificação de possiveis figuras de retórica.

A obra do período colonial brasileiro abordada neste estudo é a cantata acadêmica Heroe, egregio, douto, peregrino para soprano, dois violinos e continuo. Ainda gozando do status de obra erudita mais antiga descoberta no Brasil (Salvador, 1759), essa cantata composta em duas partes - Recitativo e Ária - foi o centro de polêmicas discussões a respeito de sua autoria: após ter sido designada ao português Caetano Melo de Jesus (autor de um histórico tratado musical e residente na Bahia naquele periodo), permanece hoje com autoria anônima.

A partir da restauração do manuscrito pelo musicólogo Paulo Castagna (ANÔNIMO, 1997), a obra foi transcrita para um instrumento de cordas orquestral solista - o contrabaixo - e cravo (ANÔNIMO, 1999). Ela foi escolhida com o objetivo de promover o exercício de elementos de interpretação estilistica do barroco, estilo com o qual identificamos essa obra do período colonial brasileiro. Dentro do caráter didático deste trabalho, optou-se também por uma não adesão a estilos nacionais específicos, mas sim pela oportunidade de exercitar práticas que, se são mais características dos estilos francês ou italiano (HANSELL, 1974), podem ser verificadas na sintese dos goûts réünis ${ }^{3}$ do alto barroco, epitomizada na música de Bach. 


\section{2 - Aspectos da relação texto-música e figuras de retórica no Recitativo e na Aria da cantata acadêmica Heroe, Egregio}

A língua dos textos dos dois movimentos (Ex.1 e Ex.2) é o português arcaico - o que é surpreendente para o período, uma vez que o latim ainda era a língua predominante na música ocidental -, mas adequado ao contexto, se considerarmos que sua natureza lisonjeira e profana deveria ser facilmente compreendida: os textos parecem destinados a saudar a chegada do magistrado português José Mascarenhas (ANÔNIMO, 2000), designado para legislar na Bahia em meados do século XVIII.

A natureza prática $e_{1}$ aparentemente sem grandes pretensões poéticas, é evidente tanto na escolha das palavras quanto na estrutura formal. As repetições, sobretudo na Aria, parecem concebidas para servir às intenções melódicas e retóricas. Por exemplo, as quatro recorrências do trecho "Gigante mostrará, gigante mostrará; Gigante mostrará, gigante mostrará" (c.3350) aparecem depois reduzidas a três, incompletas, em "Gigante mostrará, mostrará; Gigante mostrará" (c.91101). Essa assimetria do texto é reproduzida na música, resultando numa forma musical por vezes fragmentária, cujo fraseado não obedece à quadratura que já começava a predominar na música européia a partir do início do século XVIII. Assim, os textos em questão se caracterizam mais pelos procedimentos composicionais de justaposição de trechos melódicos do que pela atenção às estruturas formais simétricas. Aparece aqui uma especulação cara à musicologia brasileira, mas cujo aprofundamento escapa ao escopo deste trabalho: esta desatenção aos cânones composicionais europeus resultaria de uma liberdade de escolha do compositor ou de um distanciamento entre a colônia e a matriz européia?

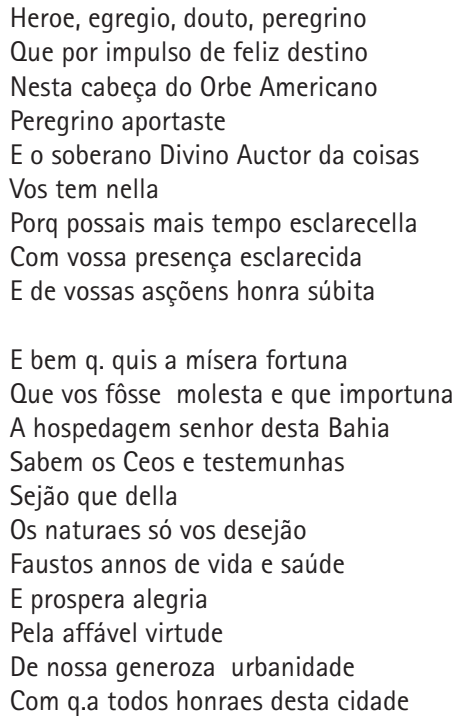

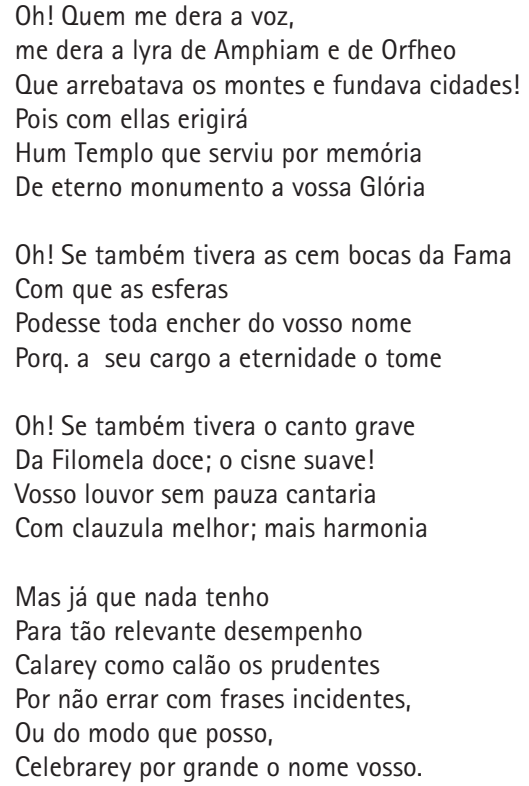

Ex.1- Letra do Recitativo da cantata acadêmica Heroe, egregio

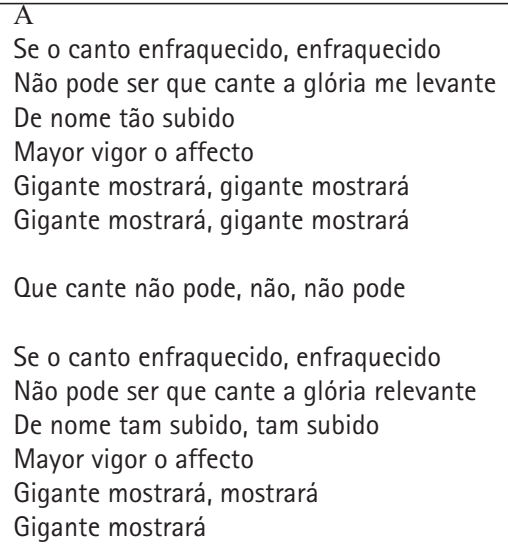

Não pode ser que cante o canto enfraquecido Mayor vigor o affecto Gigante mostrará, gigante mostrará Mostrará.

\section{B}

Pois tendo por objecto

Heroe de tal grandeza

A mesma natureza

De grande adquirirá, adquirirá. 
Independentemente da qualidade dos textos, o compositor buscou expressar musicalmente o seu caráter apologético. Alguns exemplos encontrados no Recitativo são:

- as semicolcheias anacrústicas do motivo inicial dirigindo-se para o agudo no seu início (c.12) preparando a lisonjeira introdução: "Heroe, egregio,douto, peregrino...";

- o súbito acorde de dominante da dominante apoiando o verbo de ação "...aportaste..." (c.11);

- a tonalidade da tônica maior de Fá (c.28) sob a frase "sabem os Ceos ..." em contraste com a imediata tônica menor que a precede no primeiro tempo do mesmo compasso:

- a emulação de um glissando nas cordas sugerindo o arpejo e sonoridade da lira "... de Orpheo..." (c.45);

- 0 agrupamento das colcheias descendentes inicialmente em tercinas e depois duas a duas - constituindo a figura conhecida como suspiro (sigh), intercalando e sublinhando o trecho "... Oh! Se também tivera o canto grave..." (c.6872), e complementando logo a seguir em "... da Filomena doce...";

- a recorrência do motivo da passagem anterior, desta vez em uma variação mais alegre, porém estática (semicolcheias em graus conjuntos ligadas duas a duas no agudo), sobre uma harmonia de dominante da dominante (c.72-73);

- e sua repetição logo em seguida, parecendo representar o bater de asas do "...Cisne suave!..." (c.74-75), agora sobre a harmonia de tônica do tom da dominante menor (Dó menor);

- ao final do Recitativo, a redução da atividade ritmicadoacompanhamento(predominantemente no estilo seccoaté então) que imerge o soprano em uma homofonia de longas notas (se aproximando mais do recitativo accompagnato), ${ }_{1}^{4}$ como um canto humilde e submisso em "...Mas já que nada tenho para tão relevante desempenho, Calarey, como calão os prudentes..." (c.80-87).

Do ponto de vista harmônico e formal, toda a divagação e honraria sugeridas no texto do Recitativo são representadas por um longo passeio que parte da tonalidade principal de Fá maior ${ }^{5}$ e a ela retorna no final, ilustrando "como calõo os prudentes". O giro tonal que pontua o texto repousa passageiramente em tonalidades intermediárias, vizinhas e homônimas, como Dó menor (c.14), Mi b maior (c.21), Fá menor (c.25), Fá maior (c.28), Ré menor (c.31), Lá menor (c.36), Mi menor (c.46), Ré menor (c.52), Sol menor (c.62) e Dó menor (c.74). Ressalta-se que a tonalidade de Mi menor (ou Dó \# menor na transcrição), a mais afastada do tom do movimento (Fá Maior, ou Ré Maior na transcrição), foi escolhida para sublinhar a longínqua "lyra de Amphiam e de Orfheo". Em todo o percurso tonal do Recitativo, também se observa uma grande predominância das funções harmônicas de acordes dominantes e de tônica que, ao se alternarem, enfatizam o caráter passageiro das tonalidades. Essas incursões tonais, gerando matizes de cores contrastantes, avivam o texto literário.

No original da Aria há uma interação motívica entre as partes da voz solista e do grupo que a acompanha, na qual a relação texto-música pode ser observada em vários pontos:

- no arpejo ascendente e ornamentado por mordentes que sublinha o sentido elevado da frase "...de nome tão subido..." (c.30), o qual ainda é reforçado pelo direcionamento para o tom da dominante, que se instala (c.32) e permanece até o final da primeira seção (c.54);

- no enérgico movimento melódico do trecho em que a dominante é repetida diversas vezes e com ornamentação enfática (c.32-33) sobre as palavras "...mayor vigor o affecto...";

- no longo melisma sobre a sílaba "rá" do trecho "...gigante mostrará..." (a partir do c.35), melisma que se repete mais à frente nos c.73-78 e c.9396 e, depois, sobre a primeira sílaba da palavra "adquirirá" (c.115-122) em uma demonstração de virtuosismo que, não apenas exalta o homenageado, mas também parece aludir à estatura musical da própria solista;

- no jogo de perguntas e respostas curtas entre o soprano e o acompanhamento (c.55-58) do trecho "..Que cante não pode, não, não pode...", cujas semicolcheias repetidas do acompanhamento (c.57) apóiam o seu caráter resignado.

Do ponto de vista formal, percebemos três seções - ABA na Aria, cujas estrofes vocais são intercaladas por trechos instrumentais e organizadas da seguinte maneira:

- Seção A (c.1-107): constitui uma grande seção em forma binária $\left(a+a^{\prime}\right)$. A primeira parte se caracteriza pela introdução instrumental e sua repetição vocal abrangendo os cinco versos da primeira estrofe e cuja relação tonal parte da tônica e conclui no tom da dominante, com os instrumentos cadenciando no novo tom (c.50-54). Uma transição, construída sobre as palavras" que cante não pode, não, não pode" conduz à segunda parte a' da Seção A e ao retorno da tonalidade principal, que se caracteriza, sobretudo, pela repetição da primeira estrofe partindo da tonalidade da tônica e nela mesmo concluindo com uma cadência instrumental (c.107).

- Seção B (c.108-129): seção central comum às árias no século XVIII, possui uma extensão expressivamente mais curta do que a Seção $A$, contrastando também com esta por ter uma textura polifônica, uma harmonia que privilegia a região da relativa menor como tonalidade 
principal e por transitar menos por outras tonalidades. A cadência instrumental ao final deste trecho traz de volta a tonalidade inicial do movimento e a recondução à Seção A, indicada pelo "dal segno ao FIM".

No processo de transcrição musical, procurou-se não interferir nas figuras de retórica recorrentes em ambos os movimentos. Na entrada da voz na Ária, por exemplo, é mantida a ênfase da $4^{a}$ justa ascendente no salto semplice (um salto de intervalo consoante de $3^{\text {a }}$ ou maior; BARTEL, 1998, p.380) que sublinha "Se o canto. ..." (Ex.3, c.22). Ainda no Ex.3 (c.24-25), pode-se observar uma recorrência de synonymia (figura de repetição melódica; BARTEL, 1998, p.405-408) em uma progressão melódica descendente na qual é repetida a palavra "... enfraquecido. ..."

Também no Recitativo, muitas figuras retóricas potencializam a natureza pictórica de palavras ou idéias do texto. Por exemplo, a anabasis (ou ascensus; BARTEL, 1998, p.179-180) que enfatiza a conotação ascendente do trecho "que por impulso do feliz destino" (Ex.4a; c.7) ou, ainda, o movimento para o grave da catabasis (ou descensus; BARTEL, 1998, p.214-215) que sublinha o trecho "Oh! se tivesse 0 canto grave" (Ex.4b; c.67).

\section{3-Aspectos técnico-musicaisnainterpretação do Recitativo e da Aria da cantata acadêmica Heroe, egregio}

Os aspectos da relação texto-música e a utilização de figuras de retórica no Recitativo e na Aria da cantata acadêmica Heroe, egregio (alguns dos quais foram apontados acima), muitas vezes ocorrem entrelaçados entre si, provendo um excelente ponto de partida para uma interpretação bem fundamentada. No Recitativo, o maior desafio é manter o interesse musical, já que o texto sobre o qual a música foi construída foi suprimido com a parte vocal. Assim, sugere-se uma opção pela variedade e ampliação dos contrastes para sublinhar seu conteúdo. A natureza mais ou menos positiva das palavras, 0 caráter das inflexões, o contorno melódico, as tensões e relaxamentos das progressões harmônicas e o modo de início e conclusão das frases dão ao intérprete uma ampla gama de possibilidades de retenção ou adiantamento do tempo, de valorização dos silêncios, de ênfase das dinâmicas nos momentos mais agitados ou reflexivos e mesmo de mudança de timbre.

TARLING (2000, p.218) e HURAY (1990, p.101) citam diversos autores de tratados barrocos (Quantz, Pasquali, Telemann, Heinichen, Niedt, Mattheson e Türk) para concluir que a prática de acompanhamento mais corrente no recitativo secco era tocar os acordes arpejados e curtos, mesmo quando a notação incluia notas longas, para que a textura não obnubilasse a condução melódica. Entretanto, TARLING (2000, p.219) distingue gradações do "acompanhamento curto" (short accompaniment), 0 qual pode ser realizado mais curto para as palavras (e ritmos) mais agitadas, e menos curto para as palavras (e ritmos) mais reflexivas e lânguidas. No nosso Recitativo, predominam as características do recitativo secco, no qual se observam as interferências do acompanhamento somente ao final das frases da voz solista. Entretanto, as pontuações do acompanhamento não se limitam a simples acordes, mas geralmente incluem frases mais longas e com desenvolvimento motívico, gerando um intenso padrão dialógico entre solista e grupo orquestral. Esporadicamente, ocorrem também passagens no estilo do recitativo accompagnato (c.28 -29, c.43-48 e,

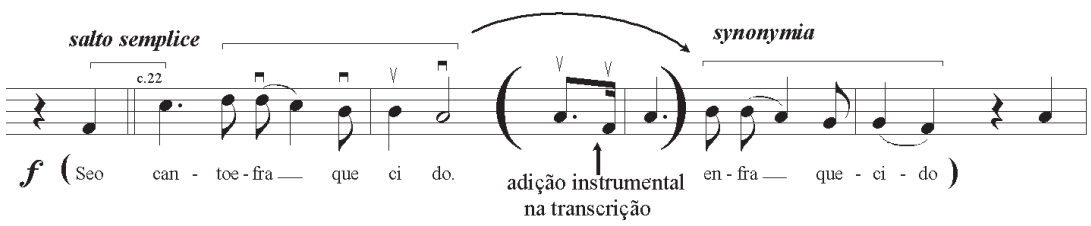

Ex.3 - Figuras retóricas do salto semplice e da synonymia no início da Aria da cantata acadêmica Heroe, egregio
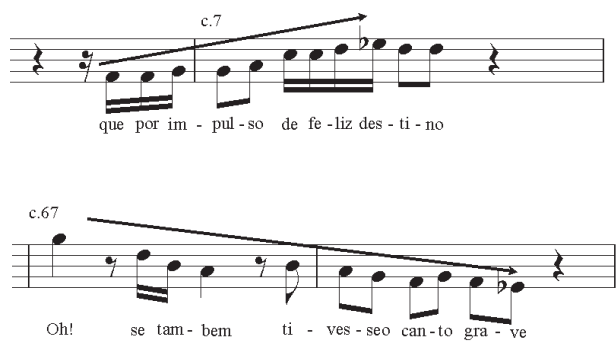

Ex.4a e $4 b$ - Figuras de retórica da anabasis e da catabasis no Recitativo da cantata acadêmica Heroe, egregio 
especialmente, c.82-87). Assim, o instrumentista solista, na transcrição, pode dispor, na maior parte do tempo, de bastante liberdade e variedade na realização do Recitativo, tanto em relação à realização rítmica, quanto em relação às sutilezas de atmosfera sugeridas pelo texto.

A redução da paleta tímbrica na instrumentação original da obra - concebida para soprano solista, dois violinos, baixo e contínuo - para apenas um instrumento solista e cravo, pode ser compensada na exploração de outras possibilidades idiomáticas desses instrumentos. 0 pizzicato, por exemplo, já era uma técnica de articulação das cordas orquestrais conhecida desde o início do Barroco, especialmente nos efeitos imitativos (TARLING, 2000, p.8), a exemplo da luta de espadas no Combattimento di Tancredi e Clorinda (1624) de Monterverdi ou dos tiros de armas de fogo nas cordas graves da Battaglia (1673) de Heinrich I. F. Biber. Já os harmônicos naturais, chamados de flageolet no barroco, aparecerem mais ao final deste período e eram utilizados com reservas. ${ }^{6}$ Entretanto, eram um recurso adotado em passagens virtuosisticas e também pelos violinistas que temiam a região aguda, como apoio para garantir uma boa afinação (TARTLING, 2000, p.75). No Ex.5, depois de quatro compassos sem tocar, o canto solista diz a pequena frase "Oh! Se também tivesse o canto grave. .." e, depois, permanece mais três compassos sem tocar. Esta intervenção do canto, de caráter catabático (vide Ex.4b acima) muda a atmosfera do discurso (seguindo, o texto diz ". . . da Filomena doce. . .o cisne suave!"). Sua interpretação pode ser realçada, na transcrição para o contrabaixo, primeiro, retendo o tempo, como em uma fala mais reflexiva. Segundo, explorando os timbres suaves dos harmônicos naturais na parte mais aguda ("Oh! Se também. ..") e dos pizzicati na parte mais grave, que para maior dramaticidade, podem ser transpostos uma oitava abaixo (",... tivesse o canto grave").

Tratemos, agora, de alguns exemplos de interpretação na Aria. Na sua transcrição, a mudança de arco para pizzicato pode ser utilizada não apenas em situações em que o interesse melódico se transfere para o teclado (c.43-46, c.82-85), mas também para sublinhar ecos e assim, enfatizar tanto a redução da dinâmica quanto a variação tímbrica (c.27-29, c.64-66, c.93-95).

A escolha de arcadas de acordo com a natureza dançante da música francesa (e consequentemente mais delicada, menos intensa e mais destacada, se comparada à italiana) tendia a valorizar arcadas mais curtas, mais articuladas e cuja ênfase nos tempos fortes favorecia sua realização com arcadas para baixo, como relata e exemplifica Georg Muffat no seu Floregium secumdum (citado por HURAY, 1990, p.26-28). Há alguns trechos, na Ária, cuja repetição de notas também sugere essa ênfase no primeiro tempo. Quando este primeiro tempo for precedido de notas repetidas ou anacrústicas, estas poderão ser articuladas mais curtas, como nos c.8-10 no cravo; ou nos c.85-89 (Ex.6) no instrumento de cordas solista.

No barroco, era comum a re-elaboração musical baseada tanto em adição quanto em subtração de notas (BORÉM, 2004). Um exemplo do primeiro caso na transcrição, semelhante ao processo de simplificação ritmica denominado Dekolorieren ou "des-ornamentação" (BENT, 1980, p.38), aparece na simplificação rítmica do motivo inicial exposto pelo cravo nos c. 1 e c. 3 - duas colcheias substituídas por uma semínima em síncopa, simplificação que depois, é repetida nos c.22 e c.24 pelo solista (Ex.7).

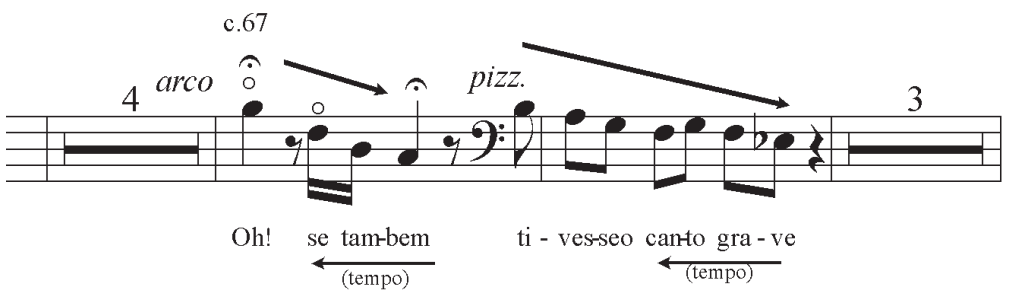

Ex.5 - Interpretação da relação texto-música em catabasis, com utilização de tempo mais reflexivo, harmônicos naturais, pizzicati e oitavação no grave do contrabaixo no Recitativo da cantata acadêmica Heroe, egregio

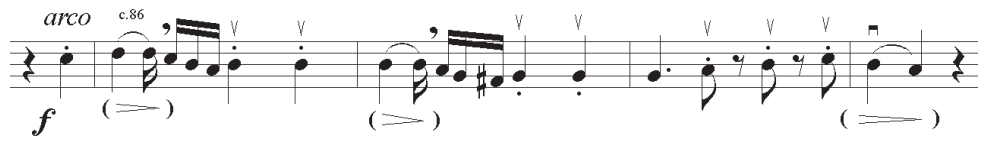

Ex.6 - Escolha de arcadas para trechos anacrústicos ou com valorização do tempo forte na Aria da cantata acadêmica Heroe, egregio 
Esta decisão é amparada pela evidência da síncopa estrutural que recorre muitas vezes ao longo da Aria (c.1213 , c. $18-19$, c. $41-42$, c. 53 , c. 59 , c. 61, c. 63 , c. 65 , c.72, c. 97 , c. 105-106, c.126, c.128 na parte do acompanhamento e, na parte do solista, nos c. 26, c. 28, c. 34, c. 41, c. 63, c. 65 , c. 72 , c. 80 , c. 88 , c. 90 , c. $96-97$ e c. 117 ).

Sabe-se que tanto a adição de notas ao original quanto o acréscimo de ornamentos com o intuito de dar movimentação e valorizar dissonâncias eram uma prática comum no barroco. No c.100 da Aria, há um acorde napolitano (ac. $N$ = Réb-Fá-Láb) que precede o acorde de sétima da dominante Si-Ré-Fá (sem a fundamental Sol) e que repousa momentaneamente sobre uma fermata. Em seguida, este progride para o acorde de Dó-Mi-Sol, o qual também repousa sobre outra fermata e finalmente alcança seu real objetivo, 0 acorde de Fá Maior (c.101), tônica da peça. Estas duas fermate propiciam um acúmulo de tensão e enfatizam a ambigüidade tonal entre Dó Maior e Fá Maior. Se na parte do cravo, ouve-se uma resolução de uma fermata para a outra, na parte da voz solista a expectativa da resolução é contrariada (a nota Fá, sétima do acorde de dominante sem a fundamental, sobe para o Sol, ao invés de descer para o Mi). Assim, o acorde de Dó maior é ambiguamente funcional: tônica com a harmonia que o precede (napolitano e dominante) e dominante com a harmonia que o segue (Fá $M$, tonalidade da peça). Neste momento de dupla suspensão do fluxo musical, entre as duas fermate, foi sugerido o acréscimo de uma pequena cadenza na transcrição da Ária, na forma de um passagio ascendente de natureza improvisatória. 0 Ex.8 mostra duas opções acrescidas à linha do instrumento solista (c.100), ambas a partir de materiais temáticos da própria Ária (a opção de cima apresenta mais uma fermata, como um repouso intermediário no movimento ascendente). Ao final da cadenza se pode observar também a valorização da dissonância na resolução cadencial sobre a tônica, também com duas opções: apojaturas simples ou dupla sobre a sensivel (c.101).

As repetições de seções ofereciam aos músicos do período barroco a oportunidade de variar melodicamente um mesmo trecho e, dessa maneira, exercitar suas habilidades improvisatórias. DART (2000, p.68-69) é enfático sobre a necessidade desta prática:

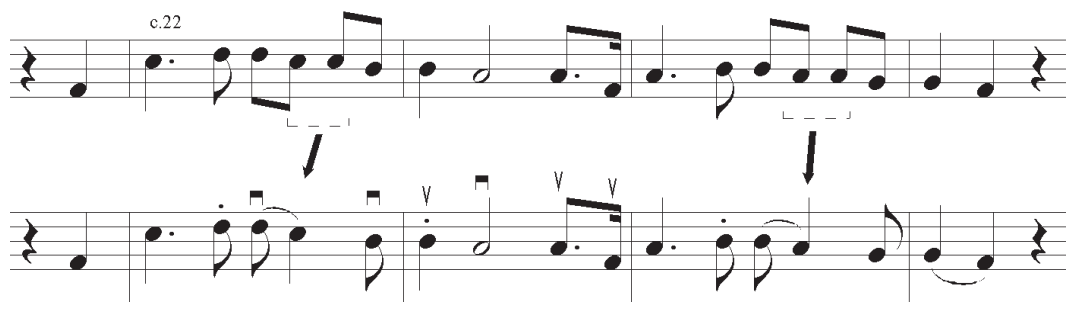

Ex.7 - Simplificação rítmica do original (pauta superior) na transcrição (pauta inferior) da Aria da cantata acadêmica Heroe, egregio

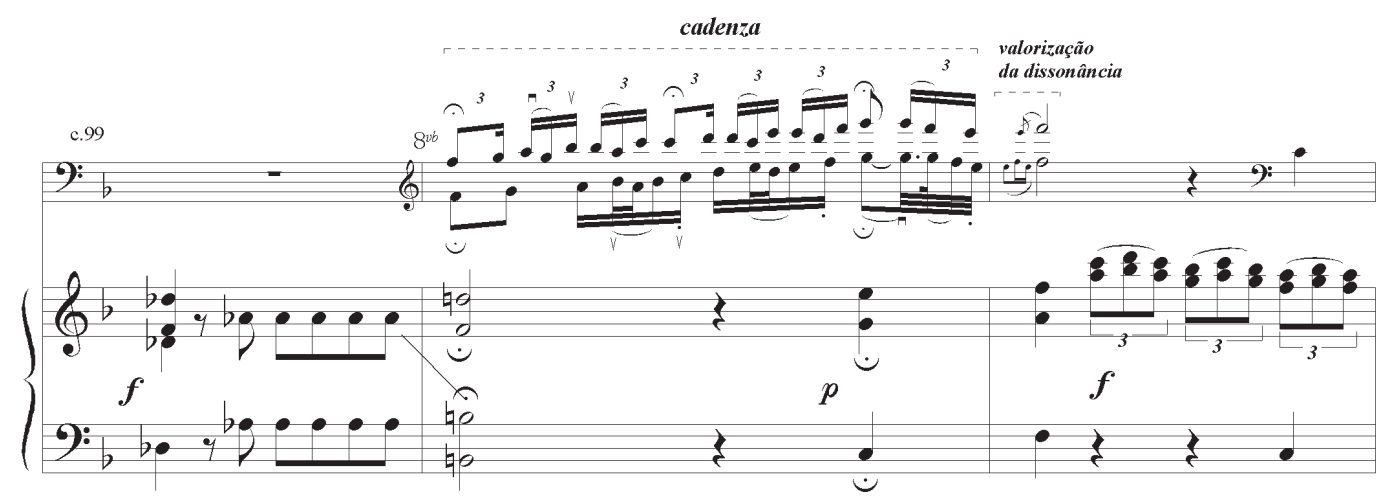

( Dó Maior: ac. $N \ldots V_{7} \ldots$

Fá Maior: $V_{7} / V \ldots \ldots$

Ex.8 - Duas opções de pequena cadenza, acrescentadas ao original da Aria da cantata acadêmica Heroe, egregio na forma de passagio e com valorização da dissonância na resolução da cadência. 
"Os intérpretes virtuosos do século XIX e de séculos anteriores eram homens de uma formação completamente diferente. No melhor dos casos, consideravam o texto do próprio compositor como um desafio à sua inventividade e a seus recursos, um elemento básico a ser embelezado aqui e ali com variações, roulades e improvisos. Ferdinand David, por exemplo, era muito admirado há uns noventa anos atrás pela habilidade com que introduzia repetições variadas na interpretação da música de Mozart e Haydn. . . qualquer intérprete do século XVIII que tocasse, digamos, a primeira parte de uma sarabanda e depois a repetisse nota por nota seria considerado um chato."

Observamos que os músicos da atualidade, em sua maioria, não exercitam práticas improvisatórias, o que era comum no período barroco. Neste sentido, a adição de ornamentos e elaborações à partitura original tem como objetivo estimular a contribuição do intérprete em uma realização mais característica do período. Assim, a recapitulação de materiais na Aria , como no motivo inicial da voz solista, nos permite intervenções que podem derivar de materiais contidos na própria obra e apresentar mudanças de articulação, provendo variedade, como demonstrado nos Exs.9a e $9 b$.
As notes inégales, com seu característico alongamento de notas na parte forte do tempo e encurtamento na parte fraca do tempo (TARLING, 2000, p.124127), podem ser emuladas (mesmo com os arcos e instrumentos modernos) em trechos contendo graus conjuntos que podem ser agrupados dois-a-dois, como nos c. 108-111 (Ex.10).

Da mesma forma, em que pese a maior dificuldade de realização nos arcos modernos, o efeito da messa di voce ou enfler, no qual o início da nota é atacado discretamente e seguido de um leve crescendo e decrescendo (TARLING, 2000, p.124-127), pode ser experimentado em notas de maior duração, como pode ser visto nos crescendi / decrescendi sugeridos entre parênteses no Ex.9b.

A prática comum das dinâmicas contrastantes forte e piano (terraced dynamics), ou ecos, como diz DONINGTON (1982, p.33), mesmo que não explicitadas na partitura, podem ser aplicadas a trechos sugeridos pela repetição

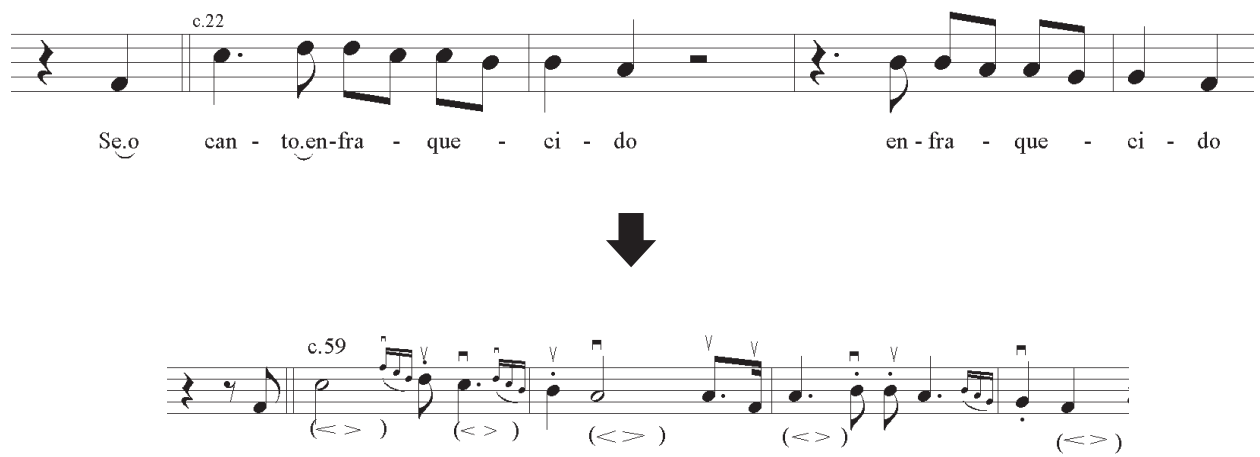

Exs.9a e $9 b$ - Trecho original e trecho da transcrição repetido com variações na Aria da cantata acadêmica Heroe, egregio

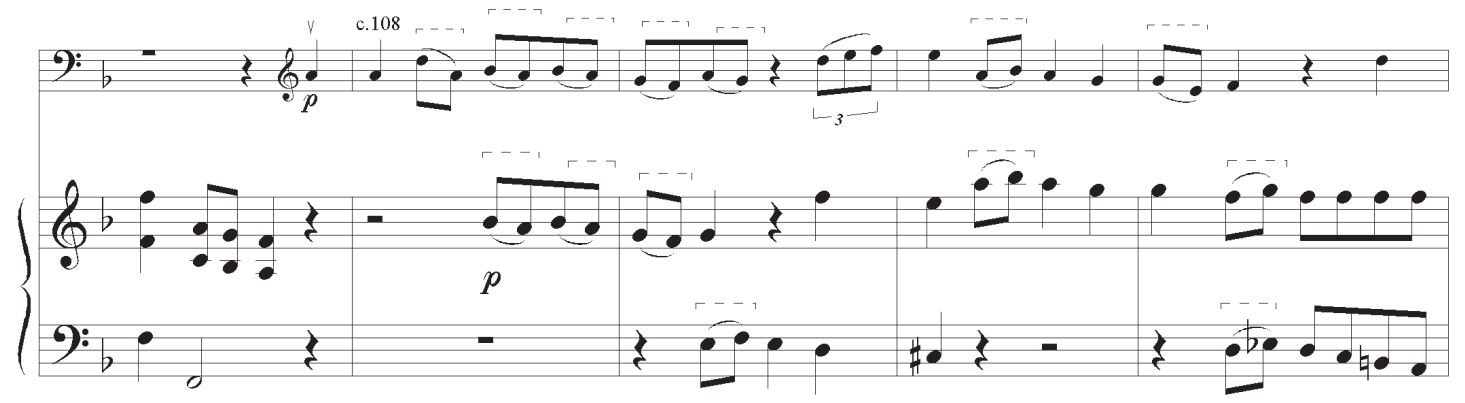

Ex.10 - Realização de notes inégales na Aria da cantata acadêmica Heroe, egregio 
de frases, como mostrado no Ex.11, cujo efeito pode ser ampliado pela mudança de timbre (de arco para pizzicato) e registro (de agudo para grave) no contrabaixo, mudanças que podem ser também reforçadas no cravo, dependendo dos tipos de recursos disponíveis como variação de timbres, manuais e registros disponiveis.

Em relação à flexibilidade no andamento, TARLING (2000, p.180) chama atenção para a possibilidade de uma maior liberdade rítmica nos conjuntos instrumentais menores (como é caso desta transcrição, para dois instrumentos apenas). Especialmente nos momentos em que o ritmo harmônico do baixo é mais lento ou estacionário, o rubato, ou efeito de "fantasia" ou o efeito de cadenza podem fazer parte da imaginação do solista, como demonstra TARLING (2000, p.138) nas sonatas de Biber e Schmelzer. Já HURAY (1990, p.126), com base no tratado de Leopoldo Mozart, discute o caso em que a qualidade expressiva de notas sob uma mesma ligadura pode ser realçada se "A primeira nota de uma ligadura fosse segurada um 'pouco mais', de maneira que a ligadura dê fluência à música, imprimindo a ela o sutil toma-edevolve que é um dos esteios da performance musical." Na Aria, estes procedimentos podem ser utilizados no motivo de semicolcheias que aparece nos c.74 e c.76 do Ex.12 e é recorrente em vários outros momentos da peça (c.95-96, c.104-105, c. 116 , c. $123-125$ e c. 127$)$.

Em relação à questão das dinâmicas, muitas vezes não explicitadas pela notação, GEMINIANI (1952, cf. Ex.XVIII, 9th e 10th) faz uma analogia entre as habilidades do orador em elevar e abaixar o tom da voz durante o discurso e a necessidade de dar direção à melodia. TARLING (2000, p.19) lembra que a abordagem retórica da música barroca emula, em última análise, "uma imitação da linguagem e da voz que declama no estilo oratório... É impossivel imaginar um discurso apresentado sem ênfases ou sem um leque de dinâmicas". Ela sugere a utilização de "um estilo declamatório moderado com ênfases fortes e fracas, gradações de dinâmicas e não apenas introduzindo acentos nas notas dos tempos fortes." Alguns exemplos referentes à supracitada proposição podem ser extraídos da transcrição da Aria, como as síncopes, o uso dos pizzicatos, as mudanças de registros, e as variadas articulações. Com relação ao padrão comum de apoio nos tempos fortes, TARLING $(2000$, p.19) lembra que, ocasionalmente, este procedimento pode ceder lugar à ênfase no segundo tempo, como é o caso das síncopes.

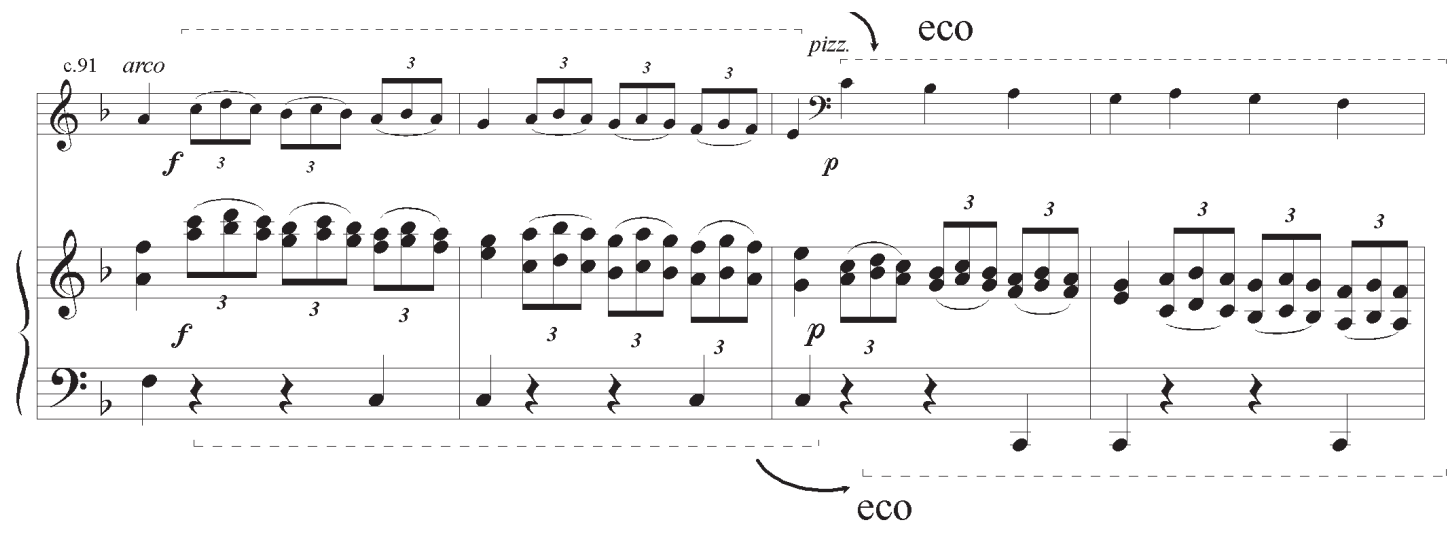

Ex.11 - Utilização de ecos na Aria da cantata acadêmica Heroe, egregio

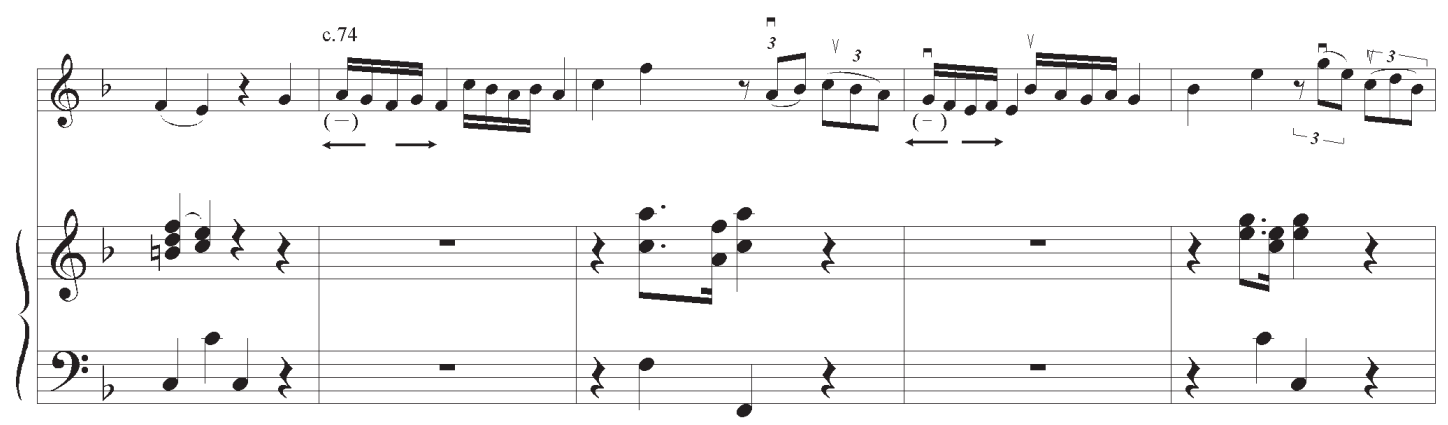

Ex.12 - Flexibilidade rítmica na interpretação da Aria da cantata acadêmica Heroe, egregio 
Outra questão central, e ainda muito polemizada, é a utilização de vibrato nos períodos barroco e clássico. Estudos recentes sobre o vibrato no violino (MILSOM, 2007), realizados a partir de análise de gravações históricas do final do século XIX e início do século XX, mostram que, mesmo ao final do período romântico, e contradizendo a crença de muitos músicos, existiu uma cultura de restrita utilização do vibrato (e maior utilização de portamenti), que pode ser exemplificada tanto por Leopold Auer, quanto por Joachim e diversos seguidores da dita escola alemã do violino (MILSOM, 2007; RODRIGUES, 2007). Embora existam amplas evidências de utilização do vibrato na literatura do período barroco (DONINGTON, 1982, p.35-37; TARLING, 2000, p.58-62; DART, 2000, p.33-34; HURAY, 1990, p.141), a maioria dos autores e especialistas opta por uma utilização discreta e esporádica do mesmo, tratando-o no como uma categoria das ornamentações. ${ }^{8}$

Finalmente, um ponto ao qual os puristas geralmente fazem reservas: a utilização, na interpretação do repertório mais antigo, de recursos composicionais que, embora já aparecessem em partituras do século XVIII, tornaram-se mais freqüentes no contrabaixo somente dentro da estética romântica do século XIX. Observa-se na partitura original um virtuosismo vocal na ponte que conduz à recapitulação da Seção A da Ária. De maneira semelhante e ressaltando a natureza virtuosística do contrabaixo moderno na transcrição, procurou-se explorar uma realização mais rica do fragmento melódico cadencial que finaliza o melisma vocal (c.120-121). Primeiro, transpondo o motivo uma oitava acima $\mathrm{e}_{\text {, }}$ depois, duas oitavas acima (Ex.13). Ainda neste mesmo trecho, recorreu-se à variação de timbres na repetição destes fragmentos, que explora a mudança de pizzicato para arco e, depois, para arco em harmônicos naturais.

\section{4 - Conclusão}

A cantata acadêmica Heroe, egregio, obra anônima de 1759 e uma das primeiras obras do período colonial brasileiro, contém diversos elementos formais, harmônicos e motívicos que a identificam (e alguns poucos que não se alinham) com a estética modelar do período barroco europeu. Tanto o Recitativo quanto a Aria, que são os dois movimentos que a compõem, podem servir como ponto de partida para o estudo deste repertório nacional ainda desconhecido da maioria dos músicos brasileiros, podendo servir também como material didático para 0 exercício de diversas práticas de performance do período. A transcrição da escrita original (soprano, dois violinos, baixo e contínuo) para uma instrumentação reduzida a um instrumento de teclado e um instrumento de cordas friccionadas solista (no caso estudado, um contrabaixo), pode auxiliar no ensino e difusão deste repertório. Sua adequação a esta nova proposta instrumental, especialmente para os instrumentos de cordas friccionadas, pode servir também ao objetivo de explorar as potencialidades idiomáticas, tímbricas e expressivas desses instrumentos, que na partitura original ficam menos aparentes pela presença do texto.

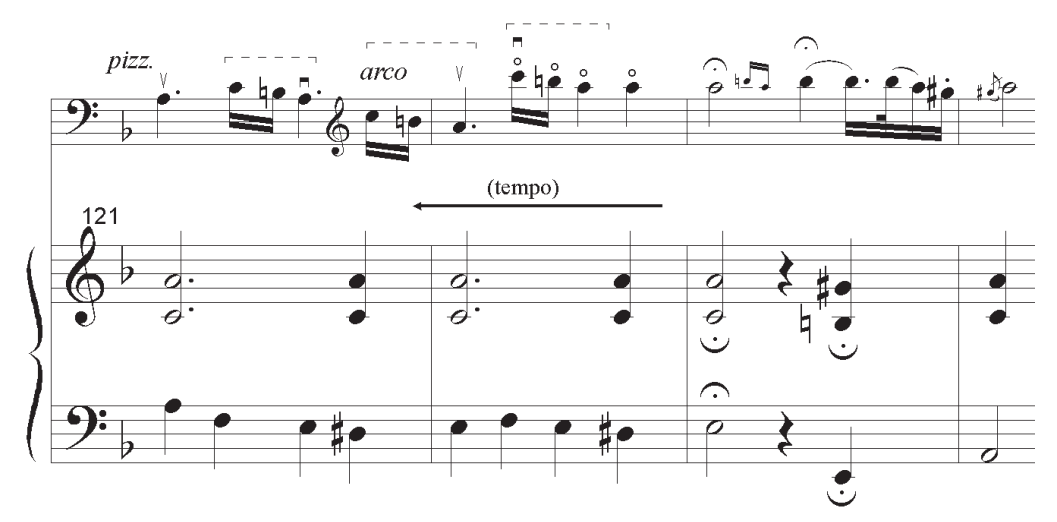

Ex.13 - Oitavações de fragmento melódico e variação timbrísica com utilização de pizzicato, arco e harmônicos naturais do contrabaixo em trecho cadencial da Aria da cantata acadêmica Heroe, egregio 


\section{Referências}

ANÔNIMO. Heroe, egregio, douto, peregrino: cantata acadêmica. Ed. Paulo Castagna São Paulo: Ed. eletrônica do Editor, 1997.

Recitativo e ária para José Mascarenhas. Ed. Régis Duprat, Maria Alice Volpe e Flávia Camargo Toni. São Paulo: USP, 2000. 178p. (Coleção Uspiana - Brasil 500 Anos). 1999.

. Heroe, egregio: Recitativo e Aria, para contrabaixo e cravo. Ed. Fausto Borém. Belo Horizonte: Musa Brasilis,

BARTEL, Dietrich. Musica poetica: musical-rhetorical figures in german baroque music. Lincoln, EUA: Nebraska University Press, 1998.

BENT, lan. Analysis. Glossário de William Drabkin. The Norton/Grove Handbooks in Music. New York: W. W. Norton, 1987.

BORÉM, Fausto. Livre ornamentação por adição e subtração em duas danças de Bach. Per Musi. v.9, jan/jun. Belo Horizonte: UFMG, 2004. p.47-63.

. Pequena história das transcrições musicais. Polifonia, v.2. São Paulo: Faculdade de Artes Alcântara Machado: 1998, p.17-30.

DART, Thurston. Interpretação da música. Trad. Mariana Czertok. Rev Eduardo Brandão. São Paulo: Martins Fontes, 2000.

DONINGTON, Robert. Style and performance: a handbook. New York: W. W. Norton, 1982.

GEMINIANI, Francesco. The art of playing the violin. Ed. David Boyden. Londres: Oxford University Press, 1952 (ed. facsimile a partir do original de 1751).

GROUT, Donald Jay; PALISCA, Claude V. A history of western music. 4ed. New York: W. W. Norton, 1988.

HANSEL, Sven. François Couperin's comparison of french and italian music. Iowa City, EUA: Ed. Autor, 1974.

HURAY, Peter Le. Authenticity in performance: eighteenth-century case studies. Cambridge: Cambridge University Press, 1990.

MILSOM, David. Lecture-recital: Beethoven, Romance Op.59; Mendelssohn, Violin Concerto (excerpts); Spohr, Violin Concerto No.9, Slow Movement (excerpts); Brahms Violin Sonata , 0p.108. Anais do CHARM RMA Annual Conference: Musicology and Recordings. Ed. Nicholas Cook e Carol Chan. Egham, Inglaterra: Royal Holloway, University of London: CHARM, 2007.

. Using early arecordings to define performance traditions: the recordings of Marie Soldat-Roeger and Arnold Rosé. Anais do CHARM RMA Annual Conference: Musicology and Recordings. Ed. Nicholas Cook e Carol Chan. Egham, inbglaterra: Royal Holloway, University of London: CHARM, 2007.

RODRIGUES, Ruth. The Auer "inheritance" or not: a comparison of vibrato styles in the recordings of Leopold Auer and Benno Rabinof. Anais do CHARM RMA Annual Conference: Musicology and Recordings. Ed. Nicholas Cook e Carol Chan. Egham, Inglaterra: Royal Holloway, University of London: CHARM, 2007.

SADIE, Stanley (Ed.). Rhetoric and music. The new Grove dictionary of music and musicians. London: Macmillan, 1980. 20v.

TARLING, Judy. Baroque string playing. St. Albans Herts, Inglaterra: Corda Music, 2000. 
Fausto Borém é Professor Associado da UFMG, onde criou o Mestrado e a Revista Per Musi. Idealizou e organizou - I Seminário Nacional de Pesquisa em Performance Musical. Coordena o grupo de pesquisa PPPMUS ("Pérolas" e "Pepinos" da Performance Musical) e o grupo de pesquisa interdisciplinar ECAPMUS (Ensino, Controle e Aprendizagem na Performance Musical), apoiados pelo CNPq, FAPEMIG e Fundo FUNDEP/UFMG, cujos resultados de pesquisa incluem um livro, três capítulos de livro, dezenas de artigos sobre práticas de performance e suas interfaces (composição, análise, musicologia, etnomusicologia e educação musical) em periódicos nacionais e internacionais, dezenas de edições de partituras e realização de recitais nos principais eventos nacionais e internacionais de contrabaixo. Recebeu diversos prêmios no Brasil (que incluem o Diapason D’Or no Brasil pela gravação de um CD com Luis Otávio Santos e a Orquestra Barroca da Pró-Música em 2006) e no exterior como solista, teórico, compositor e professor.

Cecília Nazaré de Lima é Professora Assistente do Departamento de Teoria Geral da Música da Escola de Música da UFMG. Graduada em Piano pela Fundação Universidade Mineira de Artes (FUMA), atual Universidade Estadual de Minas Gerais, e em Composição pela Escola de Música da UFMG, em 2002 concluiu o Curso de Mestrado em Artes/Música, no Instituto de Artes da Universidade Estadual de Campinas - IA/UNICAMP -, com a defesa da dissertação A fase dodecafônica de Guerra-Peixe: à luz das impressões do compositor. Atualmente leciona disciplinas relacionadas à estruturação musical e tem publicado artigos nos principais periódicos brasileiros na área de música.

Notas

0 termo cantata acadêmica foi criado pelo musicólogo Paulo Castagna quando da sua restauração e edição da obra Heroe, egregio, douto, peregrino.

20 título Sonata Sabará foi dado pelo musicólogo Domingos Sávio Lins Brandão, que restaurou e editou esta obra encontrada naquela cidade de Minas Gerais.

3 Este termo, que significa a união dos estilos francês e italiano no alto barroco, deriva do prefácio de François Couperin nos seus Les goûts reunis, oito peças de câmara publicadas em 1724 (GROUT, 1988, p.468-469).

4 Para mais detalhes sobre os estilos do recitativo secco e do recitativo accompagnato, veja TARLING (2000, p.218-220)

$5 \mathrm{Na}$ transcrição para contrabaixo, o tom original de Fá Maior foi mudado para Ré maior, no qual este giro corresponde às tonalidades de Lá menor (c.14), Dó maior (c. 21), Ré menor (c. 25), Ré maior (c. 28), Si menor (c. 31), Fá \# menor (c. 36), Do\# menor (c. 46), Si menor (c. 52), e Mi menor (c. 62), Lá menor (c. 74). Além disso, todos os exemplos neste artigo estão na tonalidade original para facilitar sua leitura pelo leitor não contrabaixista.

60 flageolet foi visto por Leopoldo Mozart como ". . . um tipo de música que causa risos..." e por Le Blanc como ". . sem ressonância, cuja pequenez não corresponde de forma alguma à sonoridade redonda das posições mais baixas." (ambos citados por TARTLING, 2000, p.75)

70 procedimento de Dekolorieren foi sistematizado por volta de 1911-1912 por Arnold Schering e aplicado aos madrigais italianos do século XIV, como o primeiro procedimento analítico de Gestalt em larga escala (BENT, 1980, p.38). 0 pesquisador do barroco Sven Hansell mencionou em aula na University of lowa (EUA), à qual estava presente o primeiro autor desse artigo, que organistas do barroco adotavam esta prática para simplificar trechos muitos elaborados.

8 Embora referências ao vibrato contínuo já apareçam no tratado de Geminiani, seu real contexto e significado da palavra "contínuo" é desconhecido e controverso. As primeiras evidências sonoras, como as gravações do violinista Joachim, que datam do final do século XIX, mostram que mesmo no periodo romântico, referências textuais sobre o vibrato contínuo não devem ser levadas em consideração literalmente (MILSON, 2007). 